www.jmscr.igmpublication.org

Impact Factor 5.84

Index Copernicus Value: 83.27

ISSN (e)-2347-176x ISSN (p) 2455-0450

crossref DOI: _https://dx.doi.org/10.18535/jmscr/v5i5.74

Journal Of Medical Science And Clinical Research

Original Article

\title{
Cytopathological changes on CIC (Conjunctival Impression Cytology) among computer users: A study of 150 cases
}

\author{
Authors \\ C.V. Kulkarni ${ }^{1}$, Ghanghoria Shikha ${ }^{2}$, Tripathi Amrita ${ }^{3 *}$ \\ ${ }^{1,2,3}$ Department of Pathology, MGM Medical College \& M.Y. Hospital, Indore \\ Corresponding Author \\ Dr Amrita Tripathi \\ Department of Pathology, MGM Medical College \& M.Y. Hospital, Indore \\ Email: tripathiamrita16@gmail.com
}

\begin{abstract}
Background: In present era, when computer use was restricted to office work; today, computer usage has extended to teaching at schools and for recreational purpose also. Therefore, excessive and rampant computer usage has led to an increase in the number of patients complaining about ocular and non-ocular symptoms related to computer use which are being grouped together as Computer Vision Syndrome (CVS). Objectives: To determine the prevalence of CVS, spread knowledge and awareness about CVS among computer users and evaluate the cytopathological changes on Conjunctival Impression Cytology (CIC) among computer user and ocular manifestations amongst computer users.

Material and Methods: Cross sectional study was conducted in Department of Pathology in MGM medical college and MY Hospital, Indore from July 2015 to June 2016.All patients underwent complete ophthalmic examination. The detailed examinations of total 150 patients were done under the following heading (history of ocular and systemic symptoms, ocular examination and CIC).

Result: Majority of the patients were in the age group of 26-30 years, Most frequent symptom were headache (67.33\%). Percentage of patients with CVS were increased with increased duration of computer use $>8$ hours was reported to be 17/19 (94.44\%). The conjunctival impression cytology findings were reported as mild dysplasia in 25 cases moderate 7 cases, severe 3 cases, 1 case was reported with Inclusion of Chlamydia trachomatis and a cellular 31 cases.

Conclusion: We found that those who used computers daily for long hours developed more CIC changes than those who worked at the computer for a shorter daily duration. Hope this study will also help in implementing corrective measures to ease the problems faced by the computer users and reduce the occurrence of CVS.

Keywords: Concunctival Impression Cytology (CIC), Computer Vision Syndrome (CVS), Computer Users.
\end{abstract}

\section{Introduction}

Computers are being used increasingly by large number of people today. Using computers has become a $21^{\text {st }}$ century necessity ${ }^{[1]}$. In present era, with excessive and rampant computer usage there has been increasing computer related health problems. This has led to an increase in the number of patients complaining about ocular and non-ocular symptoms related to computer use which are being grouped together 
as Computer Vision Syndrome (CVS).

American Optometric Association (AOA) has defined CVS as a complex of eye and vision associated problems mainly related to activities which stresses then ear vision and which are experienced in relation or during the use of computer $^{[1,2]}$

Factors accounting for CVS are duration of usage, poor lighting, screen brightness, environmental factors, vision problems \& improper work station setup also account for eye \& visual problems associated with computer. In the present study, we determine the prevalence of CVS, spread knowledge and awareness about computer vision syndrome among computer users; evaluate cytopathological changes on Conjunctival Impression Cytology (CIC) among computer user and ocular manifestations amongst computer users.

\section{Material and Methods}

Cross sectional study was conducted in Department of Pathology in in MGM medical college and MY Hospital, Indore from July 2015 to June 2016. All patients underwent complete ophthalmic examination. The detailed examinations of total 150 patients were done under the following heading: (history of ocular and systemic symptoms, ocular examination includes VA on snellen's chart, slit lamp examination, Tear film analysis and CIC).

A non-invasive method of impression cytology is done to study cellular structure. CIC was performed after anesthetizing the eye with one drop of $4 \%$ Xylocaine. Participants were asked to look down as far as possible. One person held the upper and lower lid, while the researcher held a glass slide with thumb and index finger to fix both the edges of glass slide and placed it gently onto the upper bulbar conjunctiva and was removed after 1-2 second. After taking impression over the slide it was allowed to air-dry for $1 \mathrm{~min}$ and then fixed with alcohol fixative. The slide was labeled and numbered and was received in pathology department for cytological examination. The slide was stained with PAP stain. The mounted slide was first examined under the microscope with $\times$ 10 high power field (HPF). After localization, cells were then analyzed with $\times 40 \mathrm{HPF}$ magnification. At least X10 HPF were examined for epithelial cells. The morphology of conjunctival squamous epithelial cells are studied and classified.

\section{Results}

Majority of the patients were in the age group of 26-30 years, who accounted for 61 cases i.e. $40.66 \%$ of total cases. Maximum number of patients $77(51 \%)$ were working on computer since 1-2 years. Most frequent symptom were headache $(67.33 \%)$, tired eyes $(50.66 \%)$, pain behind eyes $(49.33 \%)$ and dry eyes $(37.33 \%)$. Percentage of patients with CVS were increased with increased duration of computer use $>8$ hours was reported to be $17 / 19$ (94.44\%) (Table 1\& 2).

In our study, patients who were using computer for long hours showed dysplastic changes in their conjunctival epithelial cells. Out of 150 patients, 80 patients had normal CIC findings. Twenty five patients showed mild dys plastic changes in their CIC findings. Seven patients showed moderate dysplastic changes in their CIC findings. Three patients showed severe dysplastic changes in their CIC findings. Four patient showed acute inflammatory lesions in their CIC findings. One patient showed inclusions of Chlamydia. (Table 3\&4) (Figure 1). 


\section{JMSCR Vol||05||Issue||05||Page 21693-21697||May}

Table-1: Distribution of study participants as per Gender and Age

\begin{tabular}{|l|c|c|c|c|c|c|}
\hline \multirow{2}{*}{} & \multicolumn{2}{|c|}{ Number of Cases } & \multicolumn{2}{c|}{ CVS Symptoms } & \multicolumn{2}{c|}{ No Symptoms } \\
\cline { 2 - 7 } & Total & $\%$ & Total & $(\%)$ & Total & $(\%)$ \\
\hline Gender & 81 & 54 & 59 & 72.83 & 22 & 27.17 \\
\hline Male & 69 & 46 & 54 & 78.26 & 15 & 21.74 \\
\hline Female & 15 & 10 & 11 & 73.4 & 4 & 26.6 \\
\hline Age & 52 & 34.66 & 41 & 78.84 & 11 & 21.15 \\
\hline$<20$ Years & 61 & 40.66 & 47 & 77.04 & 14 & 22.95 \\
\hline 21-25 Years & 15 & 10 & 8 & 53.33 & 7 & 46.66 \\
\hline 26-30 Years & 7 & 4.66 & 6 & 86 & 1 & 4 \\
\hline 31-35 Years & $76-40$ Years &
\end{tabular}

\begin{tabular}{|l|c|c|c|}
\hline Table 2 : Distribution of Visual \& Other Complaints among Study Participants \\
\hline Symptom Category & CVS Symptoms & \multicolumn{2}{|c|}{ Present } \\
\cline { 2 - 4 } & & Total & $\%$ \\
\hline Ocular Symptoms & Watering eyes & 41 & 27.33 \\
\cline { 2 - 4 } & Dry eyes & 56 & 37.33 \\
\cline { 2 - 4 } & Itchy eyes & 50 & 33.33 \\
\cline { 2 - 4 } & Painbehind eyes & 74 & 49.44 \\
\cline { 2 - 4 } & Tired eyes & 76 & 50.66 \\
\cline { 2 - 4 } & Redness & 57 & 38 \\
\hline Visual symptoms & Blurred vision & 59 & 39.33 \\
\cline { 2 - 4 } & Double vision & 42 & 28 \\
\hline Systemic symptoms & Shoulder pain & 49 & 32.66 \\
\cline { 2 - 4 } & Neck pain & 58 & 38.66 \\
\cline { 2 - 4 } & Back pain & 101 & 67.33 \\
\cline { 2 - 4 } & Headache & 101 & 67.33 \\
\hline
\end{tabular}

Table 3 : Distribution of cases according to CIC findings in computer users

\begin{tabular}{|l|c|c|c|c|c|c|}
\hline \multirow{2}{*}{ CIC Grading } & \multicolumn{2}{|c|}{ Total No. of Cases } & \multicolumn{2}{c|}{ CVS Symptoms } & \multicolumn{2}{c|}{ No Symptoms } \\
\cline { 2 - 7 } & Total & $\%$ & Total & $\%$ & Total & $\%$ \\
\hline Normal Cytology & 80 & 53.33 & 60 & 75 & 20 & 25 \\
\hline Mild Dysplasia & 25 & 16.66 & 23 & 92 & 2 & 8 \\
\hline Moderate Dysplasia & 7 & 4.66 & 6 & 85.71 & 1 & 14.28 \\
\hline Severe Dysplasia & 3 & 2 & 3 & 100 & 0 & 0 \\
\hline A celluar & 30 & 20 & 19 & 63.33 & 11 & 36.66 \\
\hline $\begin{array}{l}\text { Others } \\
\text { (Inflammatory and infective) }\end{array}$ & 5 & 3.33 & 2 & 40 & 3 & 60 \\
\hline Total & 150 & 100 & 113 & 75.33 & 37 & 24.66 \\
\hline
\end{tabular}

Table 4: Distribution of cases according to CIC findings and computer use

\begin{tabular}{|l|c|c|c|c|}
\hline \multirow{2}{*}{ CICGrading } & Total No.of Cases & \multicolumn{3}{|l|}{} \\
\cline { 2 - 5 } & $\begin{array}{c}\text { Mild } \\
\text { Dysplasia }\end{array}$ & $\begin{array}{c}\text { Moderate } \\
\text { Dysplasia }\end{array}$ & Sever Dysplasia & Acute Inflammatory lesions \\
\hline 3-6hours & 16 & 6 & 2 & 3 \\
\hline 7-8hours & 9 & 1 & 1 & 2 \\
\hline Total & 25 & 7 & 3 & 5 \\
\hline
\end{tabular}




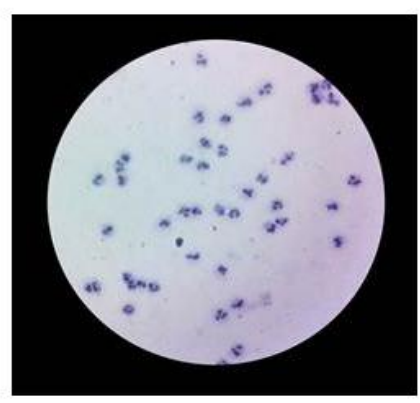

(A) Acute Inflammatory (40X)

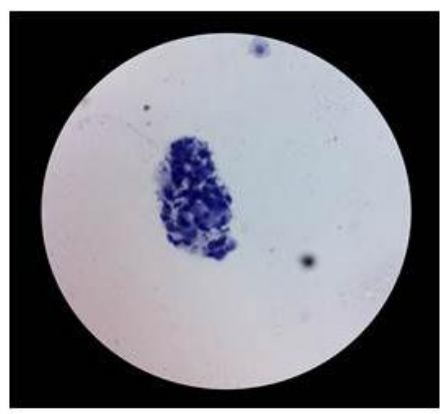

(C)

Moderate Dysplasia (40X)

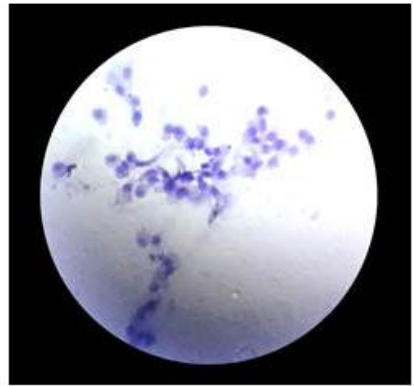

(B)

Mild Dysplasia (40X)

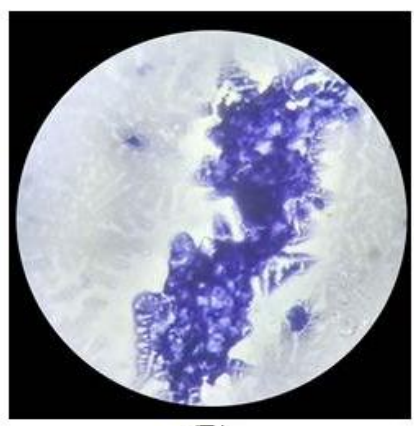

(D)

Severe Dysplasia (40X)

Figure 1: Cytopatological findings of different stages of dysplasia on CIC in CVS patients:

(A) Acute Inflammatory (40X), (B) Mild Dysplasia (40X)

(C) Moderate Dysplasia (40X), (D) Severe Dysplasia (40X)

\section{Discussion}

Dryness of eyes is a common problem worldwide and one of the frequent reasons for ophthalmic consultations. The role of personal computers and internet has increased tremendously in our day to day life. Most jobs are now computer dependent, and people have begun to spend more time in front of the computers at work, home, and even at school. Prolonged computer usage is often accompanied by dryness of eyes. ${ }^{[3]}$ CVS adds to the overall burden of dry eye in the community and has now become a significant public health problem.

The aim of the present study was to determine the prevalence of computer vision syndrome, spread knowledge and awareness about CVS among computer users and evaluate the cytopathological changes on CIC among computer user and ocular manifestations amongst computer users. The study was conducted on 150 patients out of which the prevalence of computer vision syndrome our study was observed to be $75.33 \%$.
The findings of our study were corresponding to the findings of other studies. ${ }^{[4-8]}$ The most experienced symptoms were Headache, Tired Eyes, Pain behind eyes-101/150(67.33\%), 76 $(50.66 \%) \& 74(49.33 \%)$ respectively. Balietal reported eye strain $(97.8 \%)$ and headache $(82.1 \%)$ as chief presenting symptoms of CVS in their study population ${ }^{[9]}$.

In our study CIC with abnormal tear film analysis were observed. CIC findings were reported to be showing mild dysplasia in 25 (16.66\%), moderate $7(4.66 \%)$, severe $3(2 \%)$, acute inflammatory lesions $5(3.33 \%)$ \& a cellular 31 (20.66\%). Kumar S. et al did impression cytologyin computer users and control group ${ }^{[10]}$. CIC results in control group were of stage 0 and stage I, while in computer user group showed results between stage II to stage IV. Among the computer users, the majority (>90\%) showed stage III and stage IV changes. Those who used computers daily for long hours developed more CIC changes than those who 
worked at the computer for a shorter daily duration.

Rahul Bhargava etal found measurement of TBUT, Schirmer's and CIC were abnormal in $48.5 \%, 29.1 \% \& 38.4 \%$ symptomatic computer users respectively as compared to $8 \%, 6.7 \%$ \& $7.3 \%$ symptomatic controls respectively. $\mathrm{He}$ concluded DESS should be used in combination with TBUT and CIC for dry eye evaluation in computer users ${ }^{[11]}$.

\section{Conclusion}

This showed that a person who uses computer daily for long hours develops more CIC changes than those who have a short duration of computer work. Although the sample size in our study is small, the findings are very significant. More detailed and comprehensive clinical studies to evaluate the effect of computer use on the ocular surface are necessary. This study will hopefully enlighten the public health professionals on the need of spreading awareness regarding health hazards associated with computers use. It will also help in implementing corrective measures to ease the problems faced by the computer users and reduce the occurrence of CVS.

\section{Conflict of Interests}

There was no conflict of interests with respect to all authors.

\section{Funding}

Self-funded

\section{Acknowledgment}

We sincerely appreciate the management and all staff in department of Pathology, MGM Medical College, Indore where we conduct this study.

\section{References}

1. Loh KY, Reddy SC. Understanding and preventing computer vision syndrome. Malaysian Family Physician. 2008; 3 (3): 128-30

2. American Optometric Association (2010). The effects of video display terminal use on eye health and vision. Available at: http://www.aoa.org/optometrists/education -and-training/clinical- care/effects-ofvideo-display?

3. Shantakumari N, Eldeeb R, Sreedharan J, Gopal K. Computer use and vision-related problems among university students in Ajman, United Arab emirate. Ann Med Health Sci Res. 2014; 4:258-63.

4. Sharma AK, Khera S, Khandekar J. Compute rrealted health problems among IT professionals in Delhi.CME. 2006;31 (1):36-38.

5. Talwar R. A study of Visual and Musculoskeletal Health Disorders among Computer Professionals in NCR Delhi. IJCM. 2009;34(4):326-328

6. Akinbinu T.R. Computervision syndrome: a study of knowledge and practices in university students. Nepal J Ophthalmol 2013:5(10):161-168.

7. Alemayehu M, Nega A, Tegegne E, Mule Y. Prevalence of self-reported computer vision syndrome and associated factors among secretaries and data processors who are working in university of gondar, Ethiopia. Journal of Biology, Agriculture and Healthcare. 2014;4(15):33-37.

8. Arumugam S., Kumar K., Subramani R. and Kumar S. Prevalence of Computer Vision Syndrome among Information Technology Professionals Working in Chennai. World Journal of Medical Sciences 2014; 11 (3): 312-314.

9. BaliJ,NavinN, Thakur BR. Computer vision syndrome: A study of the knowledge, attitude and practices in Indian Ophthalmologists. Indian J Ophthalmol. 2007;55:289-293

10. Kumar S , Bansal R , Khare A , Malik KPS, Malik VK, Jain K, Jain C. Conjunctival impression cytology in computer users. Nepal J Ophthalmol2013;5(9):33-37

11. Bhargava R. and Kumar P. Conjunctival Impression Cytology in Computer Users. J Ophthalmic Pathol. 2014; 3:4-16. 